Article

\title{
Sustainability Assessment of Out-of-Home Meals: Potentials and Challenges of Applying the Indicator sets NAHGAST Meal-Basic and NAHGAST Meal-Pro
}

\author{
Tobias Engelmann ${ }^{1, *}$, Melanie Speck ${ }^{2}$, Holger Rohn ${ }^{3}$, Katrin Bienge ${ }^{2}$, Nina Langen 4 (D), \\ Eva Howell ${ }^{1}$, Christine Göbel ${ }^{5}$, Silke Friedrich ${ }^{5}$, Petra Teitscheid ${ }^{5}$, Jaya Bowry ${ }^{1}$, \\ Christa Liedtke ${ }^{2}$ and Silvia Monetti ${ }^{2}$ \\ 1 Faktor 10-Institut für nachhaltiges Wirtschaften gGmbH, 61169 Friedberg, Germany; \\ eva.howell@f10-institut.org (E.H.); jaya.bowry@f10-institut.org (J.B.) \\ 2 Wuppertal Institute for Climate, Environment and Energy, 42103 Wuppertal, Germany; \\ melanie.speck@wupperinst.org (M.S.); katrin.bienge@wupperinst.org (K.B.); \\ christa.liedtke@wupperinst.org (C.L.); silvia.monetti@wupperinst.org (S.M.) \\ 3 Technische Hochschule Mittelhessen, University of Applied Sciences, 35390 Gießen, Germany; \\ holger.rohn@wi.thm.de \\ 4 Division of Food Consumption/Food Science, Institute of Vocational Education and Work Studies, \\ Technische Universität Berlin, 10623 Berlin, Germany; nina.langen@tu-berlin.de \\ 5 Institute of Sustainable Nutrition, University of Applied Sciences Münster, 48149 Münster, Germany; \\ christine.goebel@fh-muenster.de (C.G.); silke.friedrich@fh-muenster.de (S.F.); \\ petra.teitscheid@fh-muenster.de (P.T.) \\ * Correspondence: tobias.engelmann@f10-institut.org; Tel.: +49-6031-791137
}

Received: 6 December 2017; Accepted: 19 February 2018; Published: 23 February 2018

\begin{abstract}
Nutrition is responsible for about 30\% of global natural resource use. In order to limit the negative impact the nutritional sector has on the environment and on society, the consumption and processing of foodstuffs with assumed low negative impact is an important topic in the effort of sustainable development. In professional kitchens, clearly defined indicators assessing the impact of business activities are needed in this effort. The research and development in the NAHGAST project provides groundwork that could be of important assistance in this effort. Two versions of an assessment tool, with indicators of different complexity (NAHGAST Meal-Basic and NAHGAST Meal-Pro), were developed that can be used by kitchen professionals to determine the sustainability performance of their products-the offered meal. An informed selection of indicators, and a discussion of what processes and impacts this indicator relates to in the wider context, are essential and are discussed in this paper. Furthermore, in the selection of indicators for the purpose of our research certain criteria were considered simultaneously: (1) Communicability-What information an indicator can communicate and how comprehensible this information is for different actors; (2) Feasibility and data availability-Whether there is sufficient data for an indicator to be included and whether it is realistic for companies to integrate this indicator in their daily work practice; and (3) Scientific relevance-Whether the indicator is relevant for sustainability efforts on a larger scale and for related discussions in the scientific community. Insights related to these considerations are valuable for future developments in sustainability assessment in out-of-home gastronomy. The tool has been used to evaluate a number of dishes and results are deemed meaningful. However, assessments must not be understood as an accurate measurement but as an approximation of the sustainability of meals. At the level of individual indicators, they allow a detailed analysis and targeted optimization of recipes, while the aggregated results in the form of labels can be communicated well to customers. However, deficiencies and challenges, as discovered in the application phase of the project, demonstrate research gaps in the wider context. Finally, further steps for an integration of the tool in company processes and remaining options for companies to adjust the tool are discussed.
\end{abstract}


Keywords: sustainability; nutrition; sustainability assessment; indicators; out-of-home catering

\section{Introduction}

Food consumption links environmental and human health and has thus a critical role to play in promoting a more sustainable society [1-9]. According to the Food and Agricultural Organization (FAO), sustainable diets are "those diets with low environmental impacts, which contribute to food and nutrition security and to healthy life for present and future generations. Sustainable diets are protective and respectful of biodiversity and ecosystems, culturally acceptable, accessible, economically fair and affordable; nutritionally adequate, safe and healthy; while optimizing natural and human resources" [1] (p. 7).

Rising incomes, urbanization, commuting and the trend to eat of out of home more often are currently driving a global shift away from traditional diets and towards eating patterns higher in refined sugars and fats, oils, processed foods and animal products [10,11]. Due to the rising status of out-of-home catering, changes toward sustainable consumption in this sector have a great potential for also fostering change in the wider context [10-13]. Indeed, diet shifts offer practicable opportunities to reduce the environmental impact of the agro-food sector while improving human health at the same time. By offering sustainable (or at least "more sustainable") meals, the out-of-home catering sector can play a critical role in implementing the concept of "sustainable development" into consumers' everyday life [14]. As described in Lukas et al., the idea of an ecologically friendly diet is not new [15]. Leitzmann, for example, mentioned the concept of "sustainable nutrition" already in the 1970s [13].

The need for practice-oriented, recognized and standardized concepts, which can be integrated in various canteen settings to operationalize, quantify, assess and communicate food's sustainability has been acknowledged and research in this effort has increased in the last years [1]. In line with this, the development of various assessment tools can be witnessed. The FOODSCALE assessment tool [16], for example, is supposed to enable catering companies to assess the deployed foodstuffs in their processes [16]. Other research, similar to that of Wetterau (2015) [17], provides methods for the assessment and certification of the overall performance of certain catering companies [17]. The aforementioned assessment methods, however, cannot be applied to the actual products of catering companies: the single meals. In the past, assessment methods on this scale focussed primarily on health-related aspects [1]. Some work has been done on developing assessment methods that can be used on single meals and also include different sustainability dimensions. The susDISH assessment method [18], for example, allows the assessment of single meals using different sustainability criteria. The selected indicators and options to work with, read and communicate the assessment, differ from our selection and display options. In the development of the NAHGAST tool a special focus was placed on selecting indicators based on their communicability (how comprehensive they are for users), on the feasibility of their application (whether kitchen professionals can work with the indicators and the tool without the extensive help of professionals), and on scientific relevance (whether an indicator can be considered relevant in the wider sustainability context). Therefore, it provides valuable insights and groundwork for the practical implementation of such an assessment tool. As compared to assessment methods for the overall processes of companies, the tool can deliver valuable information on end products and very specific planning processes. Additionally and compared to similar assessment methods, the development of the tool considered the user environment of canteen workers and aimed to make the assistance of scientists and consultants obsolete and enable practitioners to add all necessary data themselves. Another vital part in the design of the tool development was to display the results in an easily graspable and appealing manner, also keeping the option to later utilize the tool for marketing purposes in mind. All in all, the NAHGAST tool thereby adds a valuable addition to research carried out in the effort of sustainability assessment. 
A transdisciplinary research approach allowed an in-depth analysis of kitchen processes and the determination of requirements and challenges specific for kitchen settings. Carried out in cooperation with several catering companies, the tool was constantly revised to improve its consistency, as well as its user friendliness in and relevance for canteen operations. Thus, its design not only considers scientifically relevant sustainability criteria but also the demands for implementation. We propose an innovative instrument, which will be made publicly accessible (at the end of the project in spring 2018), that displays the sustainability of single meals in a comprehensive way and at a scale- the single meal-both customers and catering companies workers can easily relate to. In this paper, we will present and discuss the theoretical as well as practical challenges that emerged during its development and implementation. Theoretical and practical challenges are not merely to be seen as fallibilities of any single assessment tool, but have to be recognized as integral areas that are in need of further research and development in order for any assessment tool aiming to evaluate the sustainability of nutrition. After having introduced the debate about sustainability in nutrition in this section, we will outline the indicators we chose to operationalize it (Section 2). This part refers to the results of earlier phases of the NAHGAST project as presented in Lukas et al. [1]. We will describe the developed methodology and the detailed functioning of the tool. The third and fourth sections outline the results of the tool's implementation and the related challenges. In the end, we will discuss the work and give an outlook on further steps and research needs (Section 5).

One general conclusion of the work is that a sustainability assessment tool for food services such as the instrument presented here is appropriate for evaluating the sustainability performance in all the tested out-of-home catering settings. It works well as starting point and tool for supporting the improvement of recipes. Based on the results, the project team was able to select meals based on sustainability criteria to further highlight them in customer-oriented interventions through nudging, participation and information. Some significant challenges, however, remain; ensuring valid data which the evaluation can be based upon and making the tool compatible with daily kitchen operations are some of the most important ones. The challenges considered in this research point to important areas in demand for further research and development.

\section{Materials and Methods}

The NAHGAST assessment tool consists of two modules, NAHGAST Meal-Basic and NAHGAST Meal-Pro. Each one encompasses different indicators [19-25]. The tool was developed based on desk research; it elaborates existing multi-criteria assessment methods as well as relevant research on selected issues related to the four dimensions of food sustainability, namely ecology, society, economy and human health. The development of the tool was mainly carried out by Faktor 10-Institut (Friedberg, Germany) and Wuppertal Institute (Wuppertal, Germany) with support of Technische Universität (Berlin, Germany) and University of Applied Sciences Münster (Münster, Germany).

In addition to desk research, the instrument was discussed in project workshops and expert meetings. Finally, it was tested on the recipes of about 100 dishes provided by companies taking part in the project. This approach allowed an incremental development, progression and optimization of the tool. In order to gain insights of the relevance of the instruments in practice, interventions were being realized in coordination in various settings within the out-of-home catering sector. In such different settings as business, care, school, and University canteens, the applicability and potential for communication and marketing strategies for consumers were analyzed for the first time. With respect to the meal assessment that this paper focuses on, a tool, working with a comprehensive definition of sustainability, was realized and tested. It additionally tries to qualify as a practical tool that can be applied by industry actors without any assistance. Instruments that feature these characteristics did not exist to date, according to our previous research. 


\subsection{Developing an Indicators-Based Assessment Tool}

Indicators can be understood as means of communication and boundary objects, mediating between and connecting science, policy and society [26]. Many different definitions for indicators exist [27-31], for the purpose of this article the definition according to Spangenberg and Bonniot (1998) can be used: indicators are a recognized instrument to make the effects of processes, production steps or end products visible and comparable [31].

Sixty indicators discussed by literature in different sustainability dimensions were analysed regarding their eligibility for their inclusion in the tool. Other tools that analyse and assess dining options were evaluated before selecting the indicators. The following concepts illustrate several useful criteria for a comprehensive approach to sustainability assessment, and have been used for the development of the NAHGAST tool:

- DGE quality standards [32];

- FOODSCALE [16];

- Certification concept "Ausgezeichnete Gemeinschaftsgastronomie" ("Excellent community catering") [17,33,34];

- Menü-Nachhaltigkeits-Index (“Menu sustainability index”) (MNI) [35];

- Nachhaltigkeitssiegel für die Betriebsgastronomie ("Sustainability label for business canteens" [36];

- Nutritional Footprint [37];

- $\quad$ susDISH [18].

An excerpt of the considered indicators in the ecological dimension of sustainability is shown in Table 1. As for all dimensions (ecologic, social, health), indicators were first grouped in different thematic clusters (for the ecological dimension: natural resource requirement, greenhouse gas emissions, other) and, subsequently, the ones to be used in the assessment tool were selected. The selection is based upon evaluating three criteria:

1. Communicability: The NAHGAST tool is supposed to enable catering companies to gain a deeper understanding of the nutritional value of a certain meal and the wider impact it has on the environment or on social issues. Moreover, the assessment results are to be used for communicating this impact to customers. Thus, how easy it is for practitioners and consumers to comprehend a certain indicator was an important criterion for deciding on its inclusion.

2. Feasibility: The NAHGAST tool is intended to be used by practitioners without the necessity of assistance by scientists or consultants. Therefore, the information to be entered must be easily obtainable by kitchen staff. Also considered were the expected expenses and human resources for preparing and entering the data.

3. Scientific relevance: As the NAHGAST tool is designed to be implemented in out-of-home catering facilities of larger scale, the potential for improving the impact their meals have on the wider context can expected to be substantial. Therefore, a selection of indicators of high scientific value was of central interest to the project team.

Evaluating the indicators based on these three criteria, they were discussed in several project workshops and expert meetings and a value was assigned to each criterion (columns labelled " $\mathrm{A}$ ", " $\mathrm{B}$ ", " $\mathrm{C}$ " in Table 1). In the end, the indicators with a good score in these criteria were selected to be included in the tool and received an asterisk $\left(^{*}\right)$ in the table below.

Some indicators were considered but were finally not selected for the inclusion. For example, emissions or activities that foster eutrophication or acidification $\left(\mathrm{N}_{2} \mathrm{O}, \mathrm{NO}_{2}, \mathrm{NH}_{3}, \mathrm{SO}_{2}, \mathrm{H}_{2} \mathrm{~S}, \mathrm{HCI}\right.$, $\mathrm{N})$ were finally dismissed due to their low communicability and moderate scientific relevance. The indicator "influence on biodiversity" was selected because of its high scientific and social relevance, however, this indicator is yet to be defined. Quantifying a meal's "influence on biodiversity" is particularly difficult, due to the issue's high complexity and lack of both accepted methodologies and sound data. 
Table 1. Selection of ecological indicators (source: [25]).

\begin{tabular}{|c|c|c|c|c|c|c|}
\hline Indicator & Ecological Category & A & B & C & Selection & Argumentation of Selection \\
\hline \multicolumn{7}{|c|}{ Natural resource requirement } \\
\hline Material (substance) footprint per meal (g) & Resource (material) & 1 & 2 & 1 & * & \multirow{3}{*}{ High relevance for science, good communicability } \\
\hline Water demand per meal (l) & Resource (water) & 1 & 2 & 2 & * & \\
\hline Land requirement per meal $\left(\mathrm{m}^{2}\right)$ & Resource (land) & 1 & 2 & 1 & * & \\
\hline Ecological footprint per meal (global hectar) & $\begin{array}{l}\text { Integrated (area, } \\
\text { greenhouse gas potential) }\end{array}$ & 2 & 2 & 2 & & $\begin{array}{l}\text { Complex instrument, potential of conflict with i.a. land } \\
\text { requirement ([1]) }\end{array}$ \\
\hline \multicolumn{7}{|c|}{ Greenhouse gas emissions } \\
\hline Carbon footprint per meal ( $\mathrm{g} \mathrm{CO}_{2}$-eq) & Greenhouse gas potential & 1 & 2 & 1 & * & High relevance for science and communicability \\
\hline $\mathrm{CH}_{4}$ emissions per meal $(\mathrm{g})$ & Greenhouse gas potential & 3 & 2 & 2 & & Impact intersects with that of the carbon footprint \\
\hline \multicolumn{7}{|c|}{ Further aspects: } \\
\hline Share of organic foodstuffs per meal (\%) & Organic agriculture & 1 & 1 & 1 & * & $\begin{array}{l}\text { High practical relevance as well as communicability and data } \\
\text { availability (distinct verifiability) }\end{array}$ \\
\hline Share of regional foodstuff per meal (\%) & Regionality & 1 & 3 & 2 & * & $\begin{array}{l}\text { High practical relevance as well as communicability but low } \\
\text { distinct verifiability (compared to organic food) }\end{array}$ \\
\hline Share of seasonal foodstuff per meal (\%) & Seasonality & 1 & 2 & 1 & * & $\begin{array}{l}\text { High practical relevance as well as communicability but low } \\
\text { distinct verifiability (compared to organic food) }\end{array}$ \\
\hline Share of animal products per meal (\%) & Animal products & 1 & 1 & 1 & * & $\begin{array}{l}\text { High practical relevance and communicability, distinct verifiability } \\
\text { on the basis of recipes }\end{array}$ \\
\hline Share of fishing products from sustainable fishing per meal (\%) & Animal products & 1 & 1 & 1 & * & $\begin{array}{l}\text { High practical relevance and communicability, distinct verifiability } \\
\text { on the basis of established certifications }\end{array}$ \\
\hline Share of preventable food waste products per meal (\%) & Waste products & 1 & 2 & 1 & * & $\begin{array}{l}\text { High practical relevance and communicability, distinct verifiability } \\
\text { however ascertainment phase over several operating days } \\
\text { are necessary }\end{array}$ \\
\hline Type of energy supply & Energy demand & 1 & 1 & 2 & & $\begin{array}{l}\text { Sound communicability, high potential of optimization, partly } \\
\text { only medium data availability within the partner companies }\end{array}$ \\
\hline Effect on the biodiversity & Biodiversity & 1 & 3 & 1 & & $\begin{array}{l}\text { High scientific relevance as well as communicability however no } \\
\text { distinct data availability or various methods }\end{array}$ \\
\hline Application of GMO-free foodstuff & Biodiversity & 1 & 2 & 1 & ** & $\begin{array}{l}\text { High scientific relevance as well as communicability however no } \\
\text { distinct data availability (GMO-label) }\end{array}$ \\
\hline
\end{tabular}

$\mathrm{A}=$ communicability, $\mathrm{B}=$ feasibility, $\mathrm{C}=$ scientific relevance 1 = very good; $2=$ medium; 3 = not sufficient; ${ }^{*}=$ Selected indicator; ${ }^{* *}=$ the indicator is included but only used for assessments in the context of an excursus in e.g., student projects. 
In order to be meaningful, indicators should be linked to concrete figures, objectives, or benchmarks [31]. With the focus on creating an assessment tool for catering companies to determine the impact of particular products, make improvements on this level, and communicate assessment results to customers, the single meal was chosen as reference unit. On this scale, easily relatable target values could be defined. To start out with one of the major products, the assessment was preliminarily limited to main course dishes. This product type can also easily be compared across different companies. Other components that can be consumed, such as drinks and desserts, were not considered at this point; this information is also very interesting but comparisons, for example, are rather difficult, as customers can choose and combine the components optionally. If the interest of a sustainability assessment would be shifted to consumers and their total nutritional intake, more components could be added to the assessment.

The tool, as understood for the purpose of this project, is thus a method to communicate characteristics of a certain meal that relate to the ecological and social impact in the wider context of its production and also to health aspects customers can consider for evaluating its impact for consumption. It serves as a kind of reference point to which both guests of catering facilities and companies' employees can directly relate. The meal is the result of many different processes and is based on products provided by the upstream supply chains [23-25].

It was decided to create two different modules for the assessment tool that could be used for different purposes: NAHGAST Meal-Basic and NAHGAST Meal-Pro. In both sets, indicators related to the impact on ecological and social aspects of sustainability consider processes in the life cycle of a foodstuff. Indicators related to health aspect consider the nutritional composition. To what extend the various indicators can be determined depends on different factors and the complexity of the indicators varies between these two sets.

Table 2 provides a complete overview of all indicators that have been chosen for the two indicator sets.

Table 2. Overview of NAHGAST indicator sets for meals assessment (source: own work based on [25]).

\begin{tabular}{|c|c|c|c|c|}
\hline Module & Ecological Aspects & Social Aspects & Health Aspects & $\begin{array}{l}\text { Economical } \\
\text { Aspects }\end{array}$ \\
\hline \multirow{6}{*}{ NAHGAST Meal-Basic } & Share of animal products & $\begin{array}{l}\text { Share of fair-trade } \\
\text { products }\end{array}$ & Energy content (kcal) & Popularity \\
\hline & Share of seasonal products & & $\begin{array}{l}\text { Amount of fruit and } \\
\text { vegetables }(\mathrm{g})\end{array}$ & $\begin{array}{l}\text { Cost-coverage } \\
\text { ratio }\end{array}$ \\
\hline & Share of regional products & & Dietary fibres content (g) & \\
\hline & Use of GMO-free products & & & \\
\hline & $\begin{array}{l}\text { Share of sustainably caught } \\
\text { fish products }\end{array}$ & & & \\
\hline & $\begin{array}{l}\text { Share of avoidable } \\
\text { food waste }\end{array}$ & & & \\
\hline \multirow{6}{*}{ NAHGAST Meal-Pro } & Carbon footprint & & & \\
\hline & Water consumption & $\begin{array}{l}\text { Share of animal products } \\
\text { from appropriate } \\
\text { animal husbandry }\end{array}$ & Fat amount (g) & $\begin{array}{l}\text { Cost-coverage } \\
\text { ratio }\end{array}$ \\
\hline & Land requirement & & $\begin{array}{c}\text { Amount of } \\
\text { carbohydrates }(\mathrm{g})\end{array}$ & \\
\hline & Cumulative energy demand & & Thereof: sugars & \\
\hline & Influence on biodiversity & & Dietary fibres content (g) & \\
\hline & & & Salt amount (g) & \\
\hline
\end{tabular}


The Basic set currently consists of 12 indicators: 6 ecological, 1 social, 3 health and 2 economic indicators. The Pro set comprehends 14 indicators: 4 ecological, 2 social, 6 health and 2 economic indicators. Six of these indicators are applied in both sets. Additionally, the aspects of energy demand and biodiversity are also considered.

The NAHGAST Meal-Basic Set was designed as a less complex version of the assessment tool. The indicators chosen for NAHGAST Meal-Basic are predominantly those that focus upon the composition of the dishes themselves, and it was aimed to find indicators that are easy to determine by kitchen workers. The criterion "share of organic product", for example, can easily be determined by kitchen staff as it merely requires determining whether a certain component is or is not derived from organic farming. While this indicator somewhat relates to processes in the life cycle of a foodstuff, as it can only be labelled "organic" if certain production standards in the upstream processes were abided by, quantitative impact values for this indicator cannot be determined. The concrete input- and output-related impact on sustainability dimensions is not known.

For NAHGAST Meal-Pro, on the other hand, ecological indicators were chosen that indicate concrete values for the ecological effects of single ingredients. The "material footprint", for example, can evaluate the ecological impact of a component with a concrete value; in the case of material footprint this would be expressed in "grams of material necessary for the production". It was designed to make the evaluation more precise as to what impact a certain foodstuff has in its entire life cycle. This precision, however, is only possible, if reliable data is available. Therefore, the comparison of these two different sets delivered valuable insights for the practicability of its application. It is to be noted, that the measured impact of some indicators refers to the agricultural production of a raw component. For processed products, the impact of intermediate production steps is considered as well. Also, the Pro Set includes calculations that consider the transport kilometres that are expected when acquiring a foodstuff from a certain source; this information must be added manually by the kitchen staff. This also applies for the footprints resulting from the storage at the partner enterprises; ecological impacts resulting from the different cooking processes are to be integrated as part of the next revision. In conclusion, many indicators have been tested for their use in kitchen practice, the tool remains customizable and certain indicators could be added in future revisions to provide consideration of a more comprehensive life cycle.

The measurement units and target levels for the Basic- and Pro-Set indicators were defined on the basis of existing literature, workshops with experts, or through own estimations if no sustainability targets existed. Subsequently, they were tested by assessing about 100 recipes provided by the companies taking part in the project. In Table 2 the target levels for the selected indicators in the Basic Set and in Table 3 the target levels for the Pro Set are shown.

For some indicators, previously defined target levels that are considered "sustainable levels" could be found in literature formulated by experts, for some of the indicators these "sustainable levels" were defined by the project team in extended discussions. It is important to acknowledge, that any type of assessment of the "sustainability" of products depends on previously defined levels that, in turn, depend on definitions of what is considered to be sustainable in the wider context. These levels can vary, depending on where the accents are set. It is important to understand though, that while the NAHGAST Tool is designed as comprehensive as possible, being able to put more emphasis on one sustainability aspect over another is a valuable component of sustainability assessment methods.

First attempts to define ecological target values or sustainable levels per meal are presented by Rohn et al. (2013) [38] and Lukas et al. (2016) [37] in reference to other authors. The main focus was to break down quantitative target values for sustainability on a larger scale to the scale of the single meal. For instance, in order to limit global warming more than $2{ }^{\circ} \mathrm{C}$, like acknowledged in the Paris Agreement, the greenhouse gas emissions in the agricultural sector need to be cut by half until 2050 [39]. As suggested in Lettenmeier (2014), the material footprint in the field of nutrition needs to be halved [40], in order to achieve a target value of 3 tons of nutrition per person and year. This would be necessary to accomplish the calculated total target value of 8 tons [41] of material consumption per 
person and year. Defining target levels for water demand has been thoroughly discussed in science and politics [42-44] but generally accepted guidelines are lacking. A proposal for a target level for water demand can be found in the concept of the nutritional footprint [37], based on various considerations in major studies in this area [42-44]. These targets and recommendations in existing studies were used to define target values for the single meal [25]. For the purpose of our study, the value of a third of an adult's daily nutritional intake was assigned to the single meal and target values were broken down accordingly.

Table 3. Target Levels NAHGAST Meal-Basic. The stated target values refer to a healthy person with an average energy consumption of $2000 \mathrm{kcal}$ per day. It is recognized that other sections of population like children, elderly or people exhibit other needs and therefor other target values (source: edited from [25]).

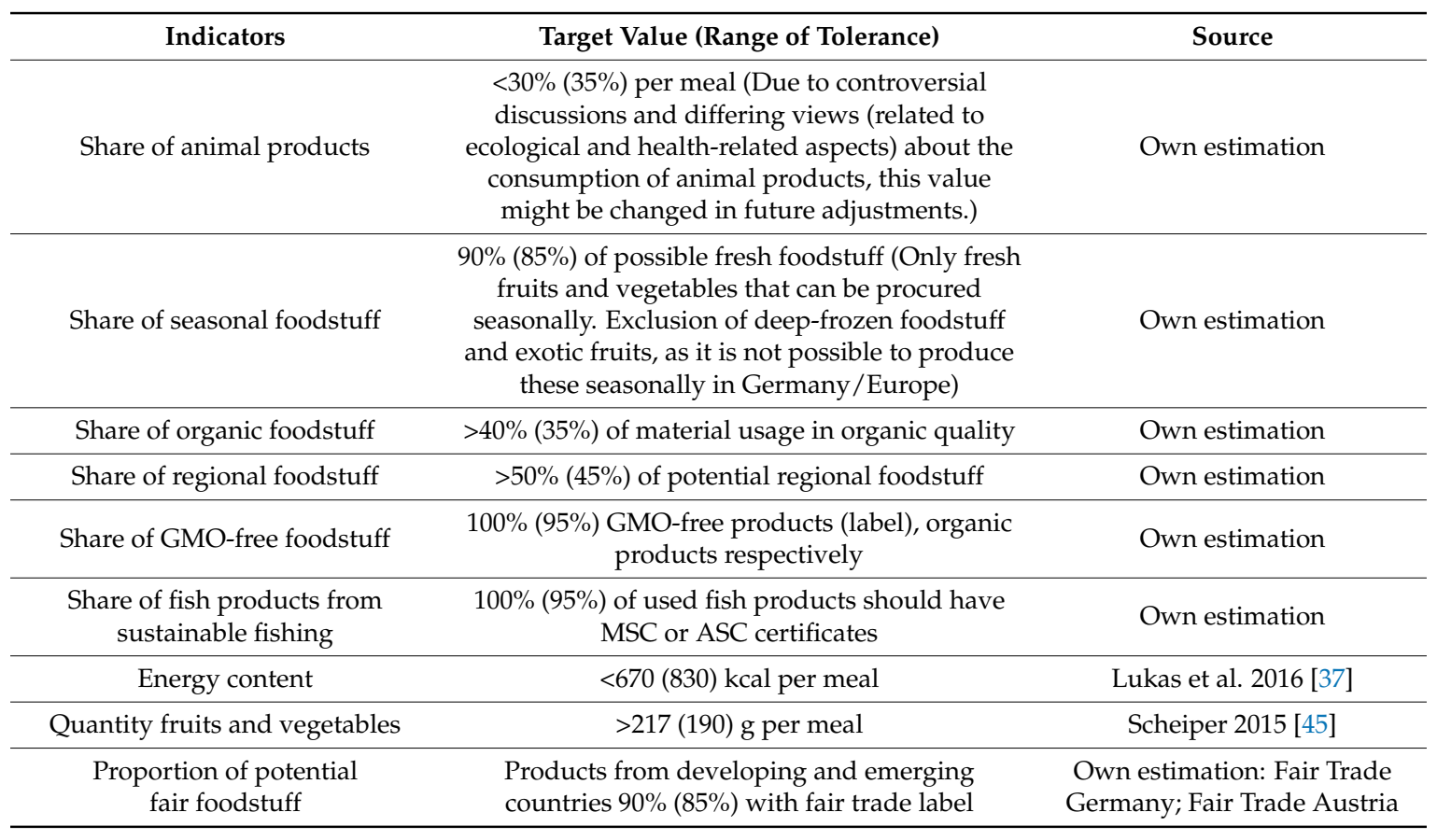

Not all indicators have sustainable target values that were previously defined in literature. The project team had to redefine these values based on own estimations [25]. For some of the chosen indicators defining targets was easier than for others. Especially those without clear and accepted standards needed to be properly defined and possibly "calibrated". The indicator "share of seasonal products (of the total potentially available seasonal products)", for example, is particularly sensitive to the time period within which it is used. Tomatoes, for instance, can be considered as "seasonal" during some months, but not during the winter. Furthermore, it had to be clarified whether or not deep-frozen or canned vegetables could be purchased seasonally and whether or not they ought to be substituted with fresh (seasonal) vegetables if available.

The values for health-related indicators were generated from various nutritive value calculators available online, in particular naehrwertrechner.de. Upon calculating the results, they were automatically connected with the manually typed in recipe data ( $120 \mathrm{~g}$ meat, $80 \mathrm{~g}$ rice, etc.) in order to generate the results automatically.

Tables 3 and 4 display that health-related and quantitative ecological indicators could mostly be derived from science. Reliable target values related to ecological, seasonal, regional, fair, GMO-free and sustainably fished ingredients based on individual meals are lacking and therefore need to be integrated as estimations in the assessment tool. 
Table 4. Target Levels NAHGAST Meal-Pro. The stated target values refer to a healthy person with an average energy consumption of $2000 \mathrm{kcal}$ per day. It is recognized that other sections of population like children, elderly or people exhibit other needs and therefor other target values (Source: edited from [25]).

\begin{tabular}{ccc}
\hline $\begin{array}{c}\text { Indicator (Indicators That Are Already } \\
\text { Listed in NAHGAST Meal-Basic Are Not } \\
\text { Illustrated Here again) }\end{array}$ & Target value “Sustainable Level" & Source \\
\hline Carbon footprint & $<800(1200)\left(\mathrm{g} \mathrm{CO}_{2 \mathrm{eq}}\right)$ per meal & Lukas et al. 2016 [37] \\
Water demand & $<640(975) 1$ per meal & Lukas et al. 2016 [37] \\
Material footprint & $<2670(4000) \mathrm{g}$ per meal & Lukas et al. 2016 [37] \\
Demand for land & $<1.25(1875) \mathrm{m}^{2}$ per meal & Lukas et al. 2016 [37] \\
Content of fibres & $>8(6) \mathrm{g}$ per meal & Lukas et al. 2016 [37] \\
Salinity & $<2(3.3)$ g per meal & Lukas et al. (2016) [37] \\
Content of carbohydrate & $<90(95)$ g carbohydrates per meal & DGE 2011c [46] \\
$\ldots$ thereof sugar & $<17(19) \mathrm{g}$ sugar per meal & DGE 2011c [46] \\
Content of fat & $24(30)$ g fat per meal & DGE 2014, Lukas et al. (2016) [38,47] \\
Share of animal products from & $<6.7(10) \mathrm{g}$ saturated fat & Own estimation \\
species-appropriate environment & $60 \%(55 \%)$ of animal products & \\
\hline
\end{tabular}

Different methodologies, formulas and sources for data must be used to calculate the different indicators and assess their performance in relation to the target values. The MIPS (Material Input per Service Unit) concept [25] provides a basis for the calculations to consider a comprehensive resource demand in the production process of a particular "service unit"; in the case of the NAHGAST tool: the single meal. For the material demand, the direct and indirect demand of abiotic (all mineral raw materials including raw materials not used for economic purposes, such as ground excavation) and biotic raw materials (mainly plant-based bio mass) are considered. For the water demand, surface, ground and deep water necessary for the production of foodstuffs is being included. The values determining a particular ecological impact, which are then used in the calculations, were derived mainly from ecoinvent 3.1 (Ecoinvent, Zurich, Switzerland) and partly from studies of the Wuppertal Institute. Since the values are not available for all ingredients, in some cases it was necessary to estimate them on the basis of similar foodstuff values.

\subsection{Functioning of the Tool}

At the time being, the NAHGAST tool is technically realized in form of an Excel file; a single file is created for every meal to be assessed. In one spreadsheet, the following meal-related information has to be entered manually:

- Recipe information (ingredients and their amount in grams);

- Some yes/no answers related to several ecological, social and health-related qualitative indicators;

- Information related to a few health-related quantitative indicators (ingredients and their amount in grams);

- Additional general and economic information.

Initially, it was expected by the project team, that the information to be filled in the NAHGAST Meal-Basic Set was going to be a lot less complex than the information to be filled in the NAHGAST Meal-Pro Set. In the end, this proved not to be the case. The reason will become clear in the following description of how the results are generated. In an in-depth discussion in Section 4, this will be elaborated. Both sets require similar data input.

To generate assessment results, the cells on the spreadsheet to input the data are connected to cells in another spreadsheet hosting the calculations. It was made possible by the project team that the spreadsheet hosting the calculations not only hosts those calculations related to the defined sustainable levels (some of which were presented in Tables 2 and 3), but also hosts quantitative data (that was found, e.g., in databanks such as ecoinvent) to convert the entered amounts of ingredients in values 
related to their impact (e.g., "grams of material used in its production"). Because this was made possible by the project team, it is not any more complex to enter data into the Pro Set as it is to enter data into the Basic set. Data related to proportions always refer to the weight of an ingredient in relation to the weight of all the ingredients of a meal. Quantitative data relate to the raw material

For both sets, a spreadsheet displaying the results is provided. For this, the entered data (e.g., $30 \%$ of the ingredients are farmed organically) are related to defined sustainable levels in the spreadsheet hosting the calculations (e.g., at least $40 \%$ of the ingredients should be organic; specific values for each indicator in the examples in Section 3) and a rating as "recommendable", "restrictively recommendable" or "not recommendable" appears. This rating is translated into numerically coded information ("recommendable" $=3$; "restrictively recommendable" $=2$; "not recommendable" = 1). The numerical values, generated for every single indicator, form the basis for calculating the overall sustainability performance. Each sustainability dimension (ecology, social, health, economy) is composed of several indicators which form a combined rating (the average value of all included indicators) and also the meal in total receives an overall score (the average value of all dimensions).Therefore, the single indicators receive a discreet number $(1=$ "not recommendable", $2=$ "restrictively recommendable", $3=$ "recommendable") and the scores in the different dimensions will have scores on a continuum between 1 and 3, since averages are calculated ( 1 to $<1.5$ means "not recommendable", 1.5 to $<2.5$ means "restrictively recommendable", 2.5 to 3 means "recommendable"). The aggregated value is generated from the average assessments of the respective indicators. In addition, colour coding emphasizes the coded information (green for "recommendable", yellow for "restrictively recommendable", red for "not recommendable").

In the NAHGAST Meal-Basic set, results can be generated by answering mostly yes/no questions. After entering a certain component with its amount in grams, several qualitative information related to this component must be added to obtain an assessment result. For some ingredients and certain information, this qualitative information is linked to a data table and filled in automatically. For example, it is automatically determined, whether the ingredient is an animal product, GMO-free, or fruit/vegetable. Whether a certain ingredient or component is seasonal, regional, organic, fair, or derived from sustainable fishery or species-appropriate husbandry, on the other hand, must be entered manually by entering " 1 " or " 0 ". This information related to a particular ingredient or component determines the proportion of a certain type of component in a dish. This proportion is then matched with the previously defined target levels for certain types of components (e.g., $40 \%$ in organic quality) within a dish and a score for this indicator is generated.

In the NAHGAST Meal-Pro version of the tool, more quantitative indicators related to single meal components are considered. In the ecologic dimension, the material and carbon footprint as well as resource and land requirements in previous production and logistics processes are considered. Sustainable levels in the NAHGAST Meal-Pro are predominately absolute target values (e.g., area required for production $<1.25 \mathrm{~m}^{2}$ per meal) as opposed to the sustainable levels defined in the Meal-Basic set, which are predominately expressed in percentages of a certain component within a meal. In the health dimension, more nutritional values are factored in.

In the last chapter in Tables 2 and 3, the sustainable target values and the corresponding sources in both modules, NAHGAST Meal-Basic and NAHGAST Meal-Pro, are listed. Meals with a score above the minimum or below the maximum sustainable level (depending on the indicator) received the appraisal "recommendable". If the values were located inside the area of tolerance the rating was labelled as "restrictively recommendable". 


\section{Applying the NAHGAST Meal-Assessment Tool}

\subsection{How the Assessment Works: An Example}

Below, we have included a fictitious example for an assessment of beef goulash. The dish consists of 11 ingredients with a total weight of $487 \mathrm{~g}$ :

- $\quad$ Beef goulash (haunch; fresh, chopped): $150 \mathrm{~g}$

- Onions (cubes, deep-frozen): $10 \mathrm{~g}$

- Sun flower oil: $10 \mathrm{~g}$

- Goulash base: $5 \mathrm{~g}$

- Wheat flour: $2 \mathrm{~g}$

- Salt: $2.75 \mathrm{~g}$

- Spices mix: $1 \mathrm{~g}$

- $\quad$ Long grain rice loose: $60 \mathrm{~g}$

- Drinking water $120 \mathrm{~g}$

- $\quad$ Mixed vegetables (deep-frozen): $120 \mathrm{~g}$

- $\quad$ Olive oil: $6 \mathrm{~g}$

With this combination of ingredients, most of the indicators miss the defined sustainable levels and the result is rather mediocre (NAHGAST Meal-Basic 1.6; NAHGAST Meal-Pro 1.8, which means: (barely) restrictively recommendable) (Tables 5 and 6).

A few general trends can be noted. Merely replacing the ingredients by, e.g., an organic or regionally produced alternative results only in a slight improvement in score, especially in NAHGAST Meal-Pro. This is due to the fact that most footprint data for regional or ecological ingredients do not differ too much from conventionally produced or globally sourced ones; also the nutritional values are quite the same. For greater improvements more substantial changes are necessary, e.g., reducing the quantity of meat, increasing the amount of (seasonal) vegetables, or substituting beef with other kinds of meat (the production of pork and chicken is connected to lower emissions of greenhouse gases). Implementing these changes allows the same recipe to reach a total score of up to 2.8 (in both NAHGAST Meal-Basic and Meal-Pro), which means "recommendable".

\subsection{Testing the Tool on Selected Recipes-Comparison of Scores}

Using the NAHGAST meal-assessment tool described in the previous section, various dishes of the participating canteens were rated. To allow a comparison of similar dishes prepared by different caterers, the dishes of the different canteens were selected in similar categories and were grouped in menu categories. 10 menu categories were defined together with the partner companies: stew (13 dishes, of which six vegetarian and three vegan); pasta (nine dishes, of which one vegetarian and three vegan); lasagna (five dishes, of which one vegetarian); potatoes (nine vegetarian and two vegan dishes); chicken (13 dishes); escallops (14 dishes, of which five vegetarian and two vegan); sausages (eight dishes, of which one vegetarian); goulash (eight dishes, of which one vegetarian and two vegan); fish (six dishes); vegan stew (nine vegan dishes). During this process, the tool was continuously reflected and improved. Certain vulnerabilities within the formulas and connections in the Excel sheet could only be detected in the process of trial on a specific meal, thus, the evaluation period was also used for methodological refinement. In addition, the tool was discussed with relevant stakeholders to incorporate external viewpoints. 
Table 5. Extract from the result spreadsheet of NAHGAST Meal-Basic (beef goulash as example).

\begin{tabular}{|c|c|c|c|c|c|c|c|c|c|c|c|c|c|}
\hline \multirow{3}{*}{$\begin{array}{c}\text { Sust. } \\
\text { Levels/Results }\end{array}$} & \multicolumn{13}{|c|}{ NAHGAST Meal-Basic-Indicators and Dimensions } \\
\hline & \multicolumn{6}{|c|}{ Ecology } & \multirow{2}{*}{$\begin{array}{c}\text { Social } \\
\% \\
\text { fair-trade } \\
\text { products }\end{array}$} & \multicolumn{3}{|c|}{ Health } & \multicolumn{2}{|c|}{ Economy } & \multirow[t]{2}{*}{ Total } \\
\hline & $\begin{array}{l}\% \text { animal } \\
\text { products }\end{array}$ & $\begin{array}{c}\% \\
\text { seasonal } \\
\text { products }\end{array}$ & $\begin{array}{c}\% \\
\text { regional } \\
\text { products }\end{array}$ & $\begin{array}{c}\% \\
\text { organic } \\
\text { products }\end{array}$ & \begin{tabular}{l}
\multicolumn{1}{c}{$\%$} \\
GMO-free \\
products
\end{tabular} & $\%$ sust. caught fish & & $\begin{array}{l}\% \text { fruits } \\
\text { and veg. }\end{array}$ & $\begin{array}{l}\text { Energy } \\
\text { (kcal) }\end{array}$ & Fibre (g) & Popularity & Cost-coverage & \\
\hline & $31 \%$ & $0 \%$ & $25 \%$ & $0 \%$ & $69 \%$ & $0 \%$ & $13 \%$ & $27 \%$ & 605 & 5.9 & level 2 & level 2 & $\begin{array}{l}\text { Weight of the } \\
\text { meal (g): } 487\end{array}$ \\
\hline Sust. level & $<30 \%$ & $>90 \%$ & $>50 \%$ & $>40 \%$ & $100 \%$ & $100 \%$ MSC / ASC /no fish & $>90 \%$ & $>40 \%$ & $<670 \mathrm{kcal}$ & $>8 \mathrm{~g}$ & level 3 & level 3 & \\
\hline Nearly sust. level & $<35 \%$ & $>85 \%$ & $>45 \%$ & $35 \%$ & $95 \%$ & $95 \%$ & $>85 \%$ & $>35 \%$ & $<830 \mathrm{kcal}$ & $>6 \mathrm{~g}$ & level 2 & level 2 & \\
\hline Results $(1,2,3)$ & 2 & 1 & 1 & 1 & 1 & 3 & 1 & 1 & 3 & 1 & 2 & 2 & \\
\hline $\begin{array}{c}\text { Results } \\
\text { (recommend.) }\end{array}$ & r. . $^{1}$ & n. r. ${ }^{2}$ & n. r. & n. r. & n. r. & $\mathrm{r}^{3}$. & n. r. & n. r. & r. & n. r. & r. r. & r. r. & Total score: $\mathbf{1 . 6}$ \\
\hline
\end{tabular}

${ }^{1}$ Restrictively recommendable; ${ }^{2}$ not recommendable; ${ }^{3}$ recommendable. Source: own work.

Table 6. Extract from the result spreadsheet of NAHGAST Meal-Pro (beef goulash as example).

\begin{tabular}{|c|c|c|c|c|c|c|c|c|c|c|c|c|c|c|c|}
\hline \multirow{3}{*}{$\begin{array}{c}\text { Sust. } \\
\text { Levels/Results }\end{array}$} & \multicolumn{15}{|c|}{ NAHGAST Meal-Pro-Indicators and Dimensions } \\
\hline & \multicolumn{4}{|c|}{ Ecology } & \multicolumn{2}{|c|}{ Social } & \multicolumn{6}{|c|}{ Health } & \multicolumn{2}{|c|}{ Economy } & \multirow[t]{2}{*}{ Total } \\
\hline & $\begin{array}{l}\text { Material } \\
\text { footpr. } \\
(\mathrm{kg})\end{array}$ & $\begin{array}{l}\text { Carbon } \\
\text { footpr. } \\
(\mathrm{kg})\end{array}$ & $\begin{array}{l}\text { Water } \\
\text { demand } \\
\text { (L) }\end{array}$ & $\begin{array}{c}\text { Area } \\
\text { required } \\
\left(\mathrm{m}^{2}\right)\end{array}$ & $\begin{array}{l}\text { Fair } \\
\text { trade }\end{array}$ & $\begin{array}{l}\text { Animal } \\
\text { welfare }\end{array}$ & $\begin{array}{l}\text { Energy } \\
\text { (kcal) }\end{array}$ & $\begin{array}{l}\text { Fibre } \\
\text { (g) }\end{array}$ & Fat (g) & $\begin{array}{l}\text { Carbo-hydr. } \\
\text { (g) }\end{array}$ & $\underset{(\mathrm{g})}{\text { Sugar }}$ & Salt (g) & Popularity & $\begin{array}{c}\text { Cost } \\
\text { coverage }\end{array}$ & \\
\hline & 9.61 & 2.39 & 169.38 & 2.59 & $13 \%$ & $0 \%$ & 605 & 5.9 & 24.8 & 58.2 & 6.1 & 3.4 & level 2 & level 2 & $\begin{array}{l}\text { Weight of the } \\
\text { meal (g): } 487\end{array}$ \\
\hline Sustainable level & $\begin{array}{c}<2.67 \\
\mathrm{~kg} / \mathrm{meal}\end{array}$ & $\begin{array}{c}<0.8 \\
\mathrm{~kg} / \text { meal }\end{array}$ & $\begin{array}{c}<640 \\
1 / \text { meal }\end{array}$ & $\begin{array}{c}<1.25 \\
\mathrm{~m}^{2} / \text { meal }\end{array}$ & $>90 \%$ & $>60 \%$ & $\begin{array}{l}<670 \\
\text { kcal }\end{array}$ & $>8 \mathrm{~g}$ & $<24 \mathrm{~g}$ & $<90 \mathrm{~g}$ & $<17 \mathrm{~g}$ & $<2 \mathrm{~g}$ & level 3 & level 3 & \\
\hline Nearly sust. level & $<4 \mathrm{~kg}$ & $<1.2 \mathrm{~kg}$ & $<975 \mathrm{~L}$ & $<1.875 \mathrm{~m}^{2}$ & $>85 \%$ & $>55 \%$ & $\begin{array}{l}<830 \\
\text { kcal }\end{array}$ & $>6 \mathrm{~g}$ & $<30 \mathrm{~g}$ & $<95 \mathrm{~g}$ & $<19 \mathrm{~g}$ & $<3.3 \mathrm{~g}$ & level 2 & level 2 & \\
\hline Results $(1,2,3)$ & 1 & 1 & 3 & 1 & 1 & 1 & 3 & 1 & 2 & 3 & 3 & 1 & 2 & 2 & \\
\hline $\begin{array}{c}\text { Results } \\
\text { (recommend.) }\end{array}$ & n. $r$. & n. $r$. & $\mathrm{r}$. & n. $r$. & n. $r$. & n. $r$. & $\mathrm{r}$. & n. r. & r. r. & r. & $\mathrm{r}$. & n. r. & r. r. & r. r. & Total score: 1.8 \\
\hline
\end{tabular}


In the table below (Table 7), selected scores are listed as example. They represent the best and the worst scoring recipes for each menu category.

Table 7. Examples of recipes scores by meal category and NAHGAST Meal indicator set (source: own work).

\begin{tabular}{|c|c|c|c|c|}
\hline \multirow{2}{*}{ Meal Category } & \multicolumn{2}{|c|}{ NAHGAST Meal-Basic } & \multicolumn{2}{|c|}{ NAHGAST Meal-Pro } \\
\hline & Min. Score & Max. Score & Min. Score & Max. Score \\
\hline \multicolumn{5}{|l|}{ 1. Stew } \\
\hline With meat & 1.6 & 2.4 & 2.2 & 3.0 \\
\hline Vegetarian & 1.8 & 2.4 & 2.3 & 2.9 \\
\hline \multicolumn{5}{|l|}{ 2. Spaghetti } \\
\hline With meat & 1.3 & 2.0 & 1.8 & 2.2 \\
\hline Vegetarian (1 option) & 1.6 & 2.4 & 2.5 & 2.9 \\
\hline \multicolumn{5}{|l|}{ 3. Lasagne } \\
\hline With meat/fish & 1.2 & 1.5 & 1.5 & 1.9 \\
\hline Vegetarian (1 option) & / & 1.8 & / & 2.5 \\
\hline \multicolumn{5}{|l|}{ 4. Potatoes } \\
\hline (Only vegetarian options) & 1.6 & 2.4 & 2.1 & 2.8 \\
\hline 5. Chicken & 1.1 & 2.2 & 1.3 & 2.5 \\
\hline \multicolumn{5}{|l|}{ 6. Cutlet } \\
\hline \multirow{2}{*}{ MeatVegetarian/vegan } & 1.2 & 2.1 & 1.8 & 2.6 \\
\hline & 1.6 & 2.1 & 2.1 & 2.5 \\
\hline \multicolumn{5}{|l|}{ 7. Sausage } \\
\hline \multirow{2}{*}{ MeatVegetarian } & 1.6 & 2.0 & 1.8 & 2.5 \\
\hline & / & 1.9 & / & 2.3 \\
\hline \multicolumn{5}{|l|}{ 8. Goulash } \\
\hline With meat & 1.2 & 1.9 & 1.8 & 2.5 \\
\hline Vegetarian & 2.0 & 2.8 & 2.5 & 2.8 \\
\hline 9. Fish & 1.2 & 2.2 & 2.0 & 2.4 \\
\hline 10. Vegan/vegetarian casserole & 1.8 & 2.6 & 2.3 & 2.8 \\
\hline
\end{tabular}

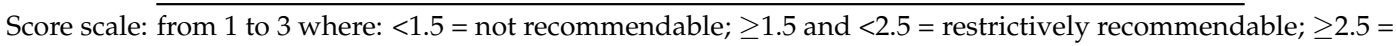
recommendable. Statistics as of March 2017.

From these results it can be noted that vegetarian/vegan meals score better, i.e., result to be overall more sustainable than meat-based ones. It must be noted that the above scores display the overall score of a meal considering ecological, social, and health-related impacts. In this comprehensive assessment, the difference between vegetarian and meat-based options is fairly small. A more differentiated comparison can be derived by looking at the different dimensions (as shown in Tables 5 and 6 and in Figure 1: ecological, social, health, economy) and, an even more differentiated comparison, by looking at the single indicators. Vegetarian and meat-based dishes can have vastly differing scores in these values. In most cases, the vegetarian dishes achieve better results in the ecological indicators than the meat-based ones do. This is not always the case, especially when large amounts of cheese are included in the meal composition. In the health indicators, vegetarian dishes often perform better in terms of, for example, saturated fatty acids. However, there are exceptions to this trend: When animal products (such as milk, cheese, etc.) are used in vegetarian dishes, the amount of fatty acids is not necessarily lower than in meat-based dishes. Vegetarian dishes also often contain a significantly higher amount of carbohydrates, which can lower the score in the overall health dimension.

It should be noted that the comparisons between meat-based and vegetarian meals (as seen in Table 7) were made using existing dishes in the regular menu plans of the practice partners. If meat-based dishes were optimized based on sustainability research and ideals and different components of the meals were substituted with alternative non-meat-based ingredients that are known for their better sustainability performance, greater improvements could be achieved. Therefore, even though assessment results generated in this project phase with the dishes of the participating 
practice partners showed only a small difference between meat-based and vegetarian dishes general conclusions cannot be derived. It can be understood as follows: The status-quo vegetarian dishes of the participating practice partners did not display a much better score than meat-based dishes because they still included ingredients that have an impact on environment, society or health that is not necessarily recommendable from a sustainability viewpoint. However, a certain "sustainability potential" can be expected when changing a meat-based dish into a vegetarian one; in order to fully realize this potential, the sustainability performance of all substituted components of the dish in various sustainability dimensions must be considered. With the NAHGAST tool it is possible to make differentiated comparisons between dishes (also between meat-based and vegetarian ones) and improvements based on this. It allows adjusting and optimizing the meal in various ways without preferential treatment of vegetarian over meat-based components but rather by looking at different impacts of different ingredients. The users of the tool can derive an aggregated result (the single score) from the meal or can look at different indicators to become familiar with a more differentiated sustainability assessment of their meals.

Moreover, the differences within the same indicator set (min. and max. scores) seem to be rather significant in almost every meal category. This hints toward differences in composition of the recipes among the different companies. Furthermore, it can be noted, that NAHGAST Meal-Pro scores are higher than those obtained through NAHGAST Meal-Basic. This will be discussed more in detail in the following section.

\subsection{Reflection of the Differences in NAHGAST Meal-Pro and Meal-Basic}

Initially, the rationale of proposing an instrument based on two modules was to provide the partner companies with two options: (1) A readily understandable indicator set (Meal-Basic) which can be utilized by practitioners without further assistance by scientific experts. (2) A more sophisticated set (Meal-Pro) encompassing several quantitative indicators which allows a more detailed, impact-oriented assessment but might require assistance by scientific experts in the calculations. This idea was based on the assumption that indicators, such as the share of organic products, are easier to understand and to deal with than impact indicators such as the carbon footprints. As already explained in previous sections, while there is a difference in complexity between these indicators, similar data has to be entered into Basic and Pro Set. Therefore, assistance by scientific experts is not necessarily needed in either one of the sets. The project team was able to incorporate most necessary formulas to calculate the data related to the different indicators automatically after entering the ingredients and amounts of the recipes.

Another finding that was discovered in the testing and application phase of the tool and has to be further reflected are the discrepancies between the results of the Basic and Pro tool. At the beginning of the project, it was assumed that both modules will lead to rather similar results, as qualitative indicators such as the share of seasonal, regional, or organic products have (more or less) strong effects on other impacts such as those measured by the carbon or the material footprint. Interestingly, this assumption proved to be partially wrong: many NAHGAST Meal-Basic scores differed from those calculated trough Meal-Pro. This implies that correlations between the qualitative and quantitative indicators should not be assumed too simple or even deterministic, although they exist.

Due to the rather small numbers of tested meals and the complexity of the issue, a statistical analysis of the discrepancies between the Basic and Pro Set was not seen as a scientifically sound option. Furthermore, to be able to fully grasp, how, e.g., a foodstuff labelled "organic" relates to an exact carbon or material footprint value, the information on the different criteria that various labelling agencies decide on their labelling (divergent certification standards exist for Demeter, Bioland, EU-Bio, labelling by the producers themselves, etc.) would have to be known. Although this is a topic that is of central interest to sustainability efforts globally, it must be formulated as a research gap for future studies. 
The NAHGAST meal-assessment tool is designed to enable catering companies to determine a sustainability direction, in which they would like to develop their products. The indicators to be included in the tool are based on elaborate research and sound scientific recommendations; these recommendations can be operationalized in a tool. However, sustainability, as the overarching effort, is not in itself a category that can be operationalized with definite figures. The information contained in the indicators can lead a company to define their goals, for example, in "decrease material/carbon footprint of meals", "improve the score on the social dimension of sustainability", "increase fibre content of meals", etc. To be able to have absolute values of sustainability, the market share of the company, the wider nutrition habits of the customers, etc. would have to be known as well as how the nutrition sector can be seen in its entirety to global development of the ecologic, social or economic realm. Therefore, there must be a clear understanding of the role an assessment tool plays in this: Any assessment tool can ever only be seen as one approach to sustainability.

Due to this, it was discussed extensively in the project team, whether a meal can be given a single score (a single overall score, and also a score for each dimension). It was decided that, as long as the score is seen as an approximation of the complex issue of sustainability, a single score can be considered valuable information in formulating goals, measuring progress, and making improvements. The fact that the indicators can be customized and are not set in stone is an advantage of the tool.

Combining the two sets in a single one was discussed. However, it is important to emphasize that the qualitative indicators are more than an intermediate step towards the quantification of impacts, and have a value of their own. In order to highlight this and to avoid an overly extensive data sheet, we decided in the end to keep the two modules separate. For future development of the tool, it is definitely important to further reflect upon the differences in the two sets. Scientific validity must always be at the forefront of the discussion; however, which set will prove more relevant for practitioners in canteens will also rely on communicability and feasibility.

\subsection{The Assessment as Basis for Further Interventions Promoting Sustainability}

The sustainability assessment also served as a basis for selecting single meals for interventions, in which the selected meals were presented to end consumers in a certain way and patterns in their behaviour were tested. This was realised in cooperation with the companies taking part in the project (five interventions with every partner).

In one intervention, meals, which received the best score in the assessment, were placed on the most frequented counters without further labelling them. The interest in this intervention was, whether certain structural features of the presentation of a meal could influence decisions; these interventions can be called "nudges". In another intervention the assessment results were translated into a label, which provided the customers with sustainability-related information about the meals they could choose to consume. The research team and also the practitioners were interested in testing whether and how individual food choices in out-of-home settings could be influenced by the communication of sustainability-related information on the meals (for more information on the NAHGAST interventions see [48]).

As far as the results of the interventions are concerned, the picture is inconsistent. By repositioning the best-scoring dishes to prominent positions in the food court, significant increases in sales could be recorded, although this was not the case for all dishes. Merely presenting the most sustainable dish with a label (as seen in Figure 1 and discussed below) did not lead to an increase in sales, even when additional information about the labels was provided. Feedback from the guests, as recorded by the kitchen staff, ranged from "positive feedback and interested inquiries" to "irritation", sometimes "disregard and disinterest". Further interventions could not be performed across all different canteen settings, but some worked well with one practice partner. For example, promoting some of the most sustainable dishes as "brainfood" led to sales increases. Also, the added incentive of a smoothie free of charge for choosing the most sustainable dish led to positive sales results. In conclusion: The label generated by the NAHGAST tool can provide a valuable addition to communication strategies, 
allowing companies to start communicating the sustainability performance of their meals to the customers. Marketing strategies for sustainable dishes must be customized for different canteen settings. Not only the settings influences the consumer choices, but also the competing dishes of the day.

Figure 1 depicts the label for a Mediterranean vegetable meal. The dish was improved by replacing rice by potatoes; the smaller carbon footprint of this substitution improved the ecological score. In addition to this, the potatoes were grown in Germany and could therefore be considered equivalent to fair trade goods, as it can be assumed that certain working and social standards are met in this area. This resulted in a good score in the social dimension. The figure below shows the label with which the restaurant was able to promote the Mediterranean vegetable dish as a particularly sustainable meal.

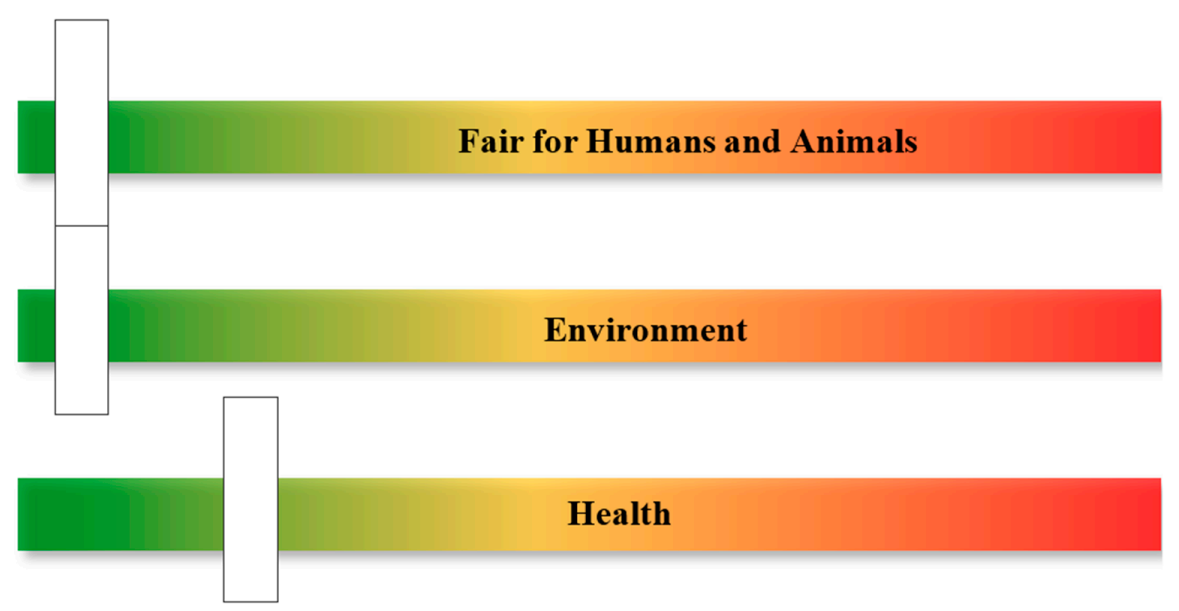

Figure 1. Label for an improved Mediterranean vegetable dish (source: own work).

This label, with values for the individual dimensions (see example above: Social—“Fair for humans and animals"-3.0, Environment 3.0, Health 2.7), is automatically generated in Excel. For this purpose, a colour gradient was implemented from green (value of 3.0) over yellow (value of 2.0) to red (value of 1.0). It must be noted, that as little information as possible is displayed in the label to allow a quick and intuitive understanding. This is also the reason for merely displaying results on the colour gradient and not as a numerical value.

\subsection{Future Possibilities for the Assessment Tool}

The necessity to enter all data manually remains to be the gravest difficulty. For each meal, very detailed information (such as amounts of single ingredients and storage-related information) has to be entered. This means that, at present, filling in NAHGAST Meal-Basic and -Pro needs more time than kitchen managers might be able to invest (about 15 minutes per meal, if the user is already familiar with the tool). A method for creating an automatized linkage between our tool and the companies' enterprise resource planning (ERP) systems could not be realized. Further projects to make the tool more compatible with companies' ERP systems have been conceptualized pending funding.

\section{Discussion of the Findings}

Findings that can be derived from the work in this project and the conception of the NAHGAST assessment tool must be seen as knowledge that can help advance the field of sustainability assessment in the future. The best practice for sustainability assessment is still a task to be negotiated between the scientific community, that will generate more knowledge about overall sustainability goals, methods, and data; political actors, that will promote and finance research and development in different areas in need; and economic players, that will or will not integrate sustainability efforts in their ventures, 
depending on whether the necessity is acknowledged and the measures to be taken are integrable in practice. Therefore, the following discussion of findings will put an emphasis on areas in need of improvement, in the tool itself but also in the wider context. It marks the current state of the tool and provides insight in the field of sustainability assessment in the nutrition sector that future work can build on.

The tool presented in this paper can be said to be consistent in itself as the calculations have been thoroughly tested and it has already served for the assessment of meals within the project. A large extent of inter-rater reliability is assumed for now, but should be tested in future improvements of the tool. Firstly, this is because for every indicator that needs manual entries instructions for infilling are given including clear indications on the assessment that needs to be given in certain cases. Secondly, part of the assessments within the NAHGAST-Project was a cross-institutional quality control that needed only minor revisions as the assessments were carried out very consistently.

However, some challenges and needs for further discussion and research remain. Working with different sets of indicators (NAHGAST Meal-Basic and Meal-Pro) and realizing, how sensitive results are to the selection of indicators, the discussion on the selection of indicators must be continued. For future research, we suggest discussing the selection of indicators based on similar categories as the ones used in this project—communicability, feasibility, scientific relevance-as an integrated view in the design of a tool is important for a successful application in the future.

Another issue to consider and that, in some cases, represented a limit to the assessment, is the fact that some indicators (such as the "share of animal products from appropriate husbandry", the "share of regional products" or the "share of fair-trade products") are not yet standardly recognized and operationalized. Defining what a "regional" product is, for example, can result to be a rather challenging task. Nevertheless, we attempted a definition of regionality: grown in a radius of less than $100 \mathrm{~km}$. To be mentioned is also the fact that some indicators (e.g., the carbon footprint) can be calculated in different ways.

Data availability represented a rather important limit as well. Indicators such as the material footprint require large amounts of data that are often incomplete or are difficult to find in a suitable form. As described above, results are generated by relating the data of the meal to the previously defined sustainable levels. The information needed for the mostly qualitative indicators of Meal-Basic is rather easy to find but Meal-Pro, quantifying nutritional and environmental impacts more precisely, requires a more comprehensive and solid data basis. For nutritional indicators comprehensive data exists, and the necessary information (e.g., the dietary fibre content of a certain food) was available in accessible databases for nearly every ingredient (for the calculations of mono products, usually the online tool naehrwertrechner.de was consulted; for the calculation of finished products, the nutritional values of producers were used). Unfortunately, this abundance of data does not exist for ecological indicators. In accessible databases such as ecoinvent, many products are not recorded and, when evaluating these products, information for similar products had to be consulted. Moreover, the products listed in the databases are generally not sufficiently nuanced to display the different possible features of a product, e.g., whether a tomato is grown seasonally, organically and open-landed, or produced in a heated greenhouse. These differences can have significant consequences for the calculation of indicators such as the carbon footprint (Table 8). Severe uncertainties were thus part of the assessment and for many products the results must be seen as approximations.

Table 8. Database examples for tomato production (source: [48]).

\begin{tabular}{cc}
\hline Database Examples for Tomato Production & $\mathbf{K g ~ C O}_{\mathbf{2}} \mathbf{~ \mathbf { q }} / \mathbf{k g}$ Tomatoes \\
\hline Conventional, regional, non-seasonal farming in heated greenhouse & 9.3 \\
Organic, regional, non-seasonal farming in heated greenhouse & 9.2 \\
Flight ware from the Canaries & 7.2 \\
Conventional farming in non-heated greenhouse & 2.3 \\
Free range tomatoes from Spain & 0.6 \\
Conventional, regional, seasonal farming & 0.085 \\
Organic, regional, seasonal farming & 0.035 \\
\hline
\end{tabular}


Therefore, in some cases, approximations were necessary. If, for example, a certain ingredient could not be found on databases such as ecoinvent, a slightly different one was chosen. Further research to integrate the data present on these databases is needed to improve the reliability of assessments such as the one presented in this work. For the indicator "influence on biodiversity" not only reliable data but also sound assessment methods are yet to be developed. Because of its importance and relevance both in the scientific and public debate, this indicator was included in the tool but, due to the lack of data, could not be calculated for the assessed meals within the project.

Overall, finding or gathering the data necessary for a sound overall assessment was often rather challenging: either they are not collected (as is the case of avoidable food waste), or companies may be reluctant to disclose them (as in the case of the exact cost-coverage ratio). Data may also be missing due to a very resource-intensive or even impossible collection (e.g., detailed information about the exact variety of certain vegetables used), or because supply chains are not fully transparent. Indeed, even big gastronomic suppliers cannot provide comprehensive information about, e.g., the exact origin of many products. Moreover, suppliers and products' origin frequently vary during the year. Nevertheless, in spite of these difficulties it was decided to keep all the selected indicators in the assessment, since they were considered relevant. If some data were missing or incomplete, the related indicators were excluded from the calculation (as in the case of avoidable food waste or the influence on biodiversity).

A further critical point is that the assessment tool could not, so far, be automatically linked to the software used by catering companies for managing their operation, especially the ERP systems (or also less sophisticated systems). With automatic linkage to an ERP system, the amount of data to manually input in the Excel files would drastically decrease. However, since different companies use very different ERP systems, the technical realization of this would go beyond the scope of the NAHGAST project. Future projects for this have been conceptualized.

Although we tried to design the tool as user-friendly as possible, it remains quite complex and, for some of its features and functioning, an explanation by scientists is necessary. A webinar was carried out to introduce the kitchen staff to several applications. This helped the participants to understand how the tool works and enabled them to use it on their own. Important to keep in mind is that potential users are usually working to capacity: the most challenging aspect to overcome is that sustainability assessment is often seen as extra work. Thus, the final aim is to design an evaluation instrument as resource-efficient as possible: easy to use without high cognitive effort and not time demanding. To realize this, the pilot study presented in this work is not enough: a longer test period is necessary.

Another decision to make, which was extensively discussed within the project, is the format in which the information is presented to canteen managers and to the end customers. A certain degree of differentiation in the information provided by the assessment is essential in order to grasp the impact a certain improvement has on different sustainability dimensions. On the other hand, information has to be concise and easily graspable.

To the catering companies, we decided to provide the following information:

Degree of differentiation:

- The evaluation of each single indicator (particularly important for identifying potential for improvement)

- The evaluation of each sustainability dimension (ecology, health, society, economy)

- The total evaluation

Type of information (for each indicator and dimension, and for the final score):

- Numerical coding (a number, decimal place holder, comprised between 1, the lowest score possible and the best performance possible)

- Belonging qualitative information (from 1 to $1.4=$ "not recommendable"; from 1.5 to $2.4=$ "restrictively recommendable"; from 2.5 to $3=$ "recommendable") 
- Belonging visual information ("not recommendable" in red, "restrictively recommendable" in yellow, "recommendable" in green)

As discussed extensively in Langen et al. 2017 [49], deciding on an appropriate format for presenting the sustainability performance of a dish to the end consumer requires some more consideration of the circumstances in which consumer decisions are made. Decisions on which option to take in canteen settings, for example, have to be made very quickly and, therefore, information has to be very concise. Based on these considerations, it was decided to present only aggregate information - an illustration of the final score as a colour-coded label.

The weighting of indicators is another option to put an emphasis on certain indicators over others and thereby accounting for certain sustainability dimensions, which are deemed more important than others. As for now, it was decided not to weight the different indicators (or dimensions). This is an issue that requires further discussion and implies a certain degree of normative decisions. Every user is thus urged to determine individually whether certain indicators are to be considered differently from others.

Also to mention is that the scientific validity must not take a back seat to the practicability. Scientific and analytical soundness, however, is a major challenge: operationalizing sustainability is a very demanding endeavour that necessarily means making oneself vulnerable to any kind of criticism.

\section{Conclusions}

Through an innovative assessment tool integrating ecological, health-related, social and economic indicators into two sets (NAHGAST Meal-Basic and Meal-Pro), we were able to evaluate a large number of recipes. The more and the less sustainable meals could be identified and the potential of recipe improvement interventions could be tested as well (e.g., sourcing seasonal, regional, organic, fair-traded products, reducing the amount of the ingredients with the highest ecological impacts or replacing them with alternative ones).

A sustainability assessment tool with a comprehensive definition of sustainability that not only allows for the evaluation of single dishes but can also be applied and customized by practitioners in the out-of-home catering sector, did not exist to date. This manifests the most important contribution of the tool for the enhancement of sustainable production and consumption patterns in this sector.

Limitations of the study are predominantly insecurities in identifying objective results through the tool. This is not an issue that can be solved for any single assessment tool, but must be seen as an overarching challenge in sustainability assessment. It has to be considered that while some sustainability indicators, such as carbon footprint or material footprint, can rely on rather reliable data from various databases (such as ecoinvent, etc.; though these databases have many gaps for certain product types), there are many other indicators in the rather complex concept of sustainability that are not sufficiently defined (e.g., regionality, seasonality), not sufficiently operationalized (e.g., influence on biodiversity) or have to be interrelated with other factors and only allow approximations.

In our view, this approximation towards a sustainability performance of a dish with the NAHGAST-tool is quite possible as the tool is well conceptualized.

The numerical and colour-coded values the tool generates are intended to break down sustainability assessment to a graspable format and enable an easy comparison of the dishes. Users should abstain from looking upon the "sustainability of dishes" with physical precision. Results are derived from different indicators and the determination of indicators is a complex issue. The selection of indicators in this project, or in similar projects, is never arbitrary but is based on intricate discussions. However, it will always be a selection of indicators; the entire picture is difficult to project. Some indicators can be objectively determined, but they might lack data to calculate them for certain foodstuffs. It is also important to understand, what can be learned from an assessment. A single dish with a good score in sustainability assessment is not necessarily "better" than a single dish with a lesser score; it must always be seen in the broader context of a person's eating habits or of companies' processes. 
Furthermore, we are aware of the difficulties that a widespread implementation would face. Major challenges for business partners are, for example, the time and effort required to use the tool or the need of gathering the necessary information. Uncertainties in the assessments also exist due to lacking data and incomplete databases for the calculations. If assessment tools should ever become a standard tool for large-scale kitchens, research and development in the collection of the necessary data must be advanced.

Integrating such an assessment in the systems used by catering companies for managing their daily operations (ERP systems) would substantially reduce the effort needed to use the tool. Developing an interface with ERP systems marks a task for a following project.

Acknowledgments: This research was carried out within the project NAHGAST funded by the German Federal Ministry of Education and Research (Grant Number 01UT1409B).

Author Contributions: This paper was written in cooperation between Tobias Engelmann, Melanie Speck, Holger Rohn, Katrin Bienge, Nina Langen, Eva Howell, Christine Göbel, Silke Friedrich, Petra Teitscheid, Jaya Bowry, Christa Liedtke, and Silvia Monetti. The development of the tool was mainly carried out by Faktor 10 -Institut and Wuppertal Institute with support of Technische Universität Berlin and University of Applied Sciences Münster. All authors made substantive intellectual contributions to the scientific content and approved the final manuscript.

Conflicts of Interest: The authors declare no conflict of interest.

\section{References}

1. Burlingame, B.; Dernini, S. Sustainable Diets and Biodiversity. Directions and solutions for policy, research and action. In Proceedings of the International Scientific Symposium: Biodiversity and Sustainable Diets United Against Hunger, Rome, Italy, 3-5 November 2010; Available online: http:/ /www.fao.org/docrep/ 016/i3004e/i3004e.pdf (accessed on 21 February 2018).

2. Sage, C. Environment and Food; Routledge: Abingdon Oxon, UK, 2012.

3. Frei, A.G.; Groß, T. Es geht um die Wurst. Vergangenheit, Gegenwart und Zukunft tierischer Kost. In Die Zukunft auf dem Tisch; Hirschfelder, G., Ploegger, A., Eds.; VS Verlag für Sozialwissenschaften: Wiesbaden, Germany, 2011; pp. 56-75.

4. Glogowski, S. Nachhaltigkeit und Ernährung: Konzepte und Grundsätze in Deutschland. Ernährungslehre und Praxis 2011, 9, 1-4.

5. Hayn, D.; Empacher, C.; Halbes, S. Trends und Entwicklungen von Ernährung im Alltag. In ErnährungswendeMaterialband; ISOE_-Institut für Sozial-Ökologische Forschung: Frankfurt, Germany, 2005; p. 107.

6. Hirschfelder, G.; Wittmann, B. Was der Mensch essen darf-Thematische Hinführung. In Was der Mensch essen darf; Hirschfelder, G., Ploeger, A., Eds.; Springer: Wiesbaden, Germany, 2015; pp. 1-13.

7. Rützler, H.; Reiter, W. Vorwärts zum Ursprung. Gesellschaftliche Megatrends und ihre Auswirkungen auf eine Veränderung unserer Esskulturen. In Die Zukunft auf dem Tisch; Hirschfelder, G., Ploeger, A., Eds.; VS Verlag für Sozialwissenschaften: Wiesbaden, Germany, 2011; pp. 77-88.

8. Vinz, D. Nachhaltiger Konsum und Ernährung. Private KonsumentInnen zwischen Abhängigkeit und Empowerment. PROKLA 2005, 1, 15-33.

9. Tilman, D.; Clark, M. Global diets link environmental sustainability and human health. Nature 2014, 515, 518-522. [CrossRef] [PubMed]

10. Rückert-John, J. Natürlich Essen: Kantinen auf dem Weg zur Nachhaltigen Ernährung; Campus Verlag: Frankfurt, Germany, 2007.

11. Rückert-John, J.; John, R. Nachhaltige Ernährung außer Haus-der Essalltag von Morgen. In Die Zukunft auf dem Tisch; Hirschfelder, G., Ploeger, A., Eds.; VS Verlag für Sozialwissenschaften: Wiesbaden, Germany, 2011; pp. 41-55.

12. Sloan, P.; Legrand, W. The Routledge Handbook of Sustainable Food and Gastronomy; Routledge: Abingdon Oxon, UK, 2015; pp. 14-55.

13. Leitzmann, C. Vegetarian nutrition: past, present, future. Am. J. Clin. Nutr. 2014, 100, 496-502. [CrossRef] [PubMed] 
14. Vieux, F.; Soler, L.-G.; Touazi, D.; Darmon, N. High nutritional quality is not associated with low greenhouse gas emissions in self-selected diets of French adults. Am. J. Clin. Nutr. 2013, 97, 569-583. [CrossRef] [PubMed]

15. Lukas, M.; Rohn, H.; Lettenmeier, M.; Liedtke, C. Assessing indicators and limits for a sustainable everyday nutrition. In Proceedings of the World Resources Forum, Davos, Switzerland, 11-14 October 2015.

16. Goggins, G.; Rau, H. Beyond. Beyond calorie counting: Assessing the sustainability of food provided for public consumption. J. Clean. Prod. 2016, 112, 257-266. [CrossRef]

17. Wetterau, J. Zertifizierungskonzept für die "Ausgezeichnete Gemeinschaftsgastronomie"; Hochschule Niederrhein: Krefeld, Germany, 2015.

18. Meier, T.; Gärtner, C. Bilanzierungsmethode susDISH: Nachhaltigkeit in der Gastronomie-Gesundheits- und Umweltaspekte in der Rezepturplanung gleichermaßen berïcksichtigen; DLG-Lebensmittel: Halle-Wittenberg, Germany, 2015.

19. Engelmann, T.; Fischer, D.; Geiger, S. Sustainability assessment in the social-ecological research for sustainable production and consumption between ideal and practice. In Proceedings of the SustEcon Conference-The Contribution of a Sustainable Economy to Achieving the Sustainable Development Goals, Freie Universität Berlin, Germany, 25-26 September 2017.

20. Engelmann, T.; Speck, M. Sustainability assessment of out of-home meals: potentials and obstacles applying indicator sets NAHGAST Meal-Basis and NAHGAST Meal-Pro. Int. J. Food Syst. Dyn. 2017, 8, 329-338.

21. Engelmann, T.; Bienge, K.; Rohn, H. Sustainable use of natural resources in different out-of-home catering settings: Sustainability assessment of meals. In Proceedings of the World Resources Forum, Geneva, Switzerland, 24-25 October 2017.

22. Engelmann, T.; Rohn, H. Bewertung von Ausgewählten Verpflegungsangeboten—Working Paper 4; NAHGAST Project: Friedberg, Germany, 2017.

23. Bienge, K.; Engelmann, T.; Speck, M.; Monetti, S.; Langen, N.; Göbel, C.; Friedrich, S.; Holger, R.; Teitscheid, P. Sustainability assessment of meals in the out-of-home catering sector: Links between the NAHGAST indicator sets and the SDGs. In Proceedings of the SustEcon Conference-The contribution of a sustainable economy to achieving the Sustainable Development Goals, Freie Universität, Berlin, Germany, 25-26 September 2017.

24. Speck, M.; Rohn, H. Usefulness of two indicator sets for sustainable out-of-home meals. In Proceeding of the ESEE 2017 Conference, Budapest, Hungary, 20-23 June 2017.

25. Speck, M.; Rohn, H.; Engelmann, T.; Schweißinger, J.; Neundorf, D.; Teitscheid, P.; Langen, N.; Bienge, K. Entwicklung von integrierten Methoden zur Messung und Bewertung von Speisenangeboten in den Dimensionen Ökologie, Soziales, Ökonomie und Gesundheit_Working Paper 2; NAHGAST Project: Wuppertal, Germany, 2017.

26. Lehtonen, M.; Sébastien, L.; Bauler, T. The multiple roles of sustainability indicators in informational governance: between intended use and unanticipated influence. Curr. Opin. Environ. Sust. 2016, 18, 1-9. [CrossRef]

27. Wu, J.; Wu, T. Sustainability indicators and indices: An overview. In Handbook of Sustainability Management; World Scientific: Singapore, 2012; pp. 65-86.

28. Heink, U.; Kowarik, I. What are indicators? On the definition of indicators in ecology and environmental planning. Ecol. Indic. 2010, 10, 584-593. [CrossRef]

29. OECD. Environmental Indicators. Development, Measurement and Use; Reference Paper; OECD: Paris, France, 2003; Volume 50.

30. Waas, T.; Hugé, J.; Block, T.; Wright, T.; Benitez-Capistros, F.; Verbruggen, A. Sustainability assessment and indicators: Tools in a decision-making strategy for sustainable development. Sustainability 2014, 6, 5512-5534. [CrossRef]

31. Spangenberg, J.H.; Bonniot, O. Sustainability Indicators: A Compass on the Road towards Sustainability; Wuppertal Papers; Wuppertal Institute for Climate, Environment and Energy: Wuppertal, Germany, 1998; Volume 81.

32. DGE-Qualitätsstandards. Available online: https://www.dge.de/gv/dge-qualitaetsstandards/\#mainContent (accessed on 7 July 2017).

33. Peinelt, V.; Wetterau, J. Prüf-Standards für die Zertifizierung und Bewertung der Verpflegung in Ganztagsschulen sowie in Kindertagesstätten; Hochschule Niederrhein: Krefeld, Germany, 2011. 
34. Peinelt, V.; Wetterau, J. Konzept für die Zertifizierung und Bewertung der Verpflegung in Ganztagsschulen sowie Kindertagesstätten; Hochschule Niederrhein: Krefeld, Germany, 2012.

35. Müller, C. Menü-Nachhaltigkeits-Index. Ein benutzerfreundliches Tool zur Nachhaltigkeitsbeurteilung von Menüs in der Gemeinschaftsgastronomie; Internal Presentation; Institute of Food and Beverage Innovation: Zürich, Switzerland, 2015.

36. Teitscheid, P. Erstes Nachhaltigkeitssiegel für die Betriebsgastronomie; FH Münster: Münster, Germany, 2011.

37. Lukas, M.; Rohn, H. The nutritional footprint-Integrated methodology using environmental and health indicators to indicate potential for absolute reduction of natural resource use in the field of food and nutrition. J. Clean. Prod. 2016, 132, 161-170. [CrossRef]

38. Rohn, H.; Lettenmeier, M.; Leismann, K.; Veuro, S.; Bowry, J. Reducing the Material Footprint of Meals. In Proceedings of the World Resources Forum Conference, Davos, Switzerland, 6-9 October 2013.

39. Smith, P.; House, J.; Bustamante, M.; Sobocká, J.; Harper, R.; Pan, G.; West, P.; Clark, J.M.; Adhya, T.; Rumpel, C.; et al. Global change pressures on soils from land use and management. Glob. Chang. Biol. 2016, 22, 1008-1028. [CrossRef] [PubMed]

40. Lettenmeier, M.; Liedtke, C.; Rohn, H. Eight Tonnes of Material Footprint-Suggestion for a Resource Cap for Household Consumption in Finland. Resources 2014, 3, 488-515. [CrossRef]

41. Schmidt-Bleek, F. Wieviel Umwelt braucht der Mensch? Faktor 10-das Maß für ökologisches Wirtschaften; Birkhäuser: Berlin, Germany, 1994.

42. Ercin, A.E.; Hoekstra, A.Y. Carbon and Water Footprints: Concepts, Methodologies and Policy Responses; UNESCO: Paris, France, 2012.

43. Hoekstra, A.Y.; Mekonnen, M.M. The water footprint of humanity. Proc. Natl. Acad. Sci. USA 2012, 109, 3232-3237. [CrossRef] [PubMed]

44. Mekonnen, M.M.; Hoekstra, A.Y. National Water Footprint Accounts: The Green, Blue and Grey Water Footprint of Production and Consumption (Value of Water. Research Report Series No. 50); UNESCO-IHE; Institute for Water Education: Delft, The Netherlands, 2011.

45. Scheiper, M.-L.; Lukas, M.; Teitscheid, P. Der Nutritional Footprint: Kritische Diskussion der gesundheitlichen Kernindikatoren und der Chancen und Grenzen der praktischen Anwendung des Instruments in der Außer-Haus-Verpflegung. In Proceedings of the FENS Conference, Berlin, Germany, 20-23 October 2015.

46. Deutsche Gesellschaft für Ernährung e.V. Evidenzbasierte Leitlinie: Kohlehydratzufuhr und Ernährungsbedingte Krankheiten. Available online: https://www.dge.de/wissenschaft/leitlinien/leitliniekohlenhydrate/ (accessed on 23 January 2018).

47. Deutsche Gesellschaft für Ernährung. DGE-Qualitätsstandard für die Betriebsverpflegung. Available online: https:/ / www.in-form.de/fileadmin/Dokumente/Materialien/DGE_Qualitaetsstandard_fuer_die_ Betriebsverpflegung_Aufl.4.pdf (accessed on 21 February 2018).

48. Langen, N.; Bauske, E.; Dubral, R. Interventions to guide consumers towards sustainable nutrition out-of-home- the perspective of caterers vs. guests. In Proceedings of the 11th International European Forum (Igls-Forum) (161st EAAE Seminar) on System Dynamics and Innovation in Food Networks, Igls, Austria, 15 February 2017.

49. Grabolle, A.; Loitz, T. Pendos $\mathrm{CO}_{2}$-Zähler; Pendo Verlag: München, Germany, 2007.

(C) 2018 by the authors. Licensee MDPI, Basel, Switzerland. This article is an open access article distributed under the terms and conditions of the Creative Commons Attribution (CC BY) license (http://creativecommons.org/licenses/by/4.0/). 